\title{
KUALITAS PELAYANAN KEPERAWATAN DI RUMAH SAKIT UMUM DAERAH (RSUD) KOTA BAUBAU
}

\author{
La Ode Syaiful Islamy $\mathbf{H}^{1 凶}$, Sulima ${ }^{1}$ \\ ${ }^{1}$ Pascasarjana Administrasi Negara Universitas Dayanu Ikhsanuddin Baubau
}

\begin{tabular}{l}
\hline ARTICLE INFO \\
\hline Article history \\
Submitted : 2019-08-18 \\
Revised : 2020-05-28 \\
Accepted : 2020-06-29 \\
\hline Keywords: \\
Service \\
Quality \\
Nursing
\end{tabular}

\section{Kata Kunci:}

Kualitas

Pelayanan

Keperawatan

\begin{abstract}
Improving service quality, availability of facilities, and independence are the demands of hospitals as the national health sub-system. Thus the hospital is required to provide quality health services and managed by resources superior nursing to create efficiency and quality of service in meeting patient needs. This research aimed to analyze the quality of nursing services in the RSUD of Baubau City by using qualitative methods where this study was more on descriptive and in-depth analysis, highlighting subjective and theoretical basis used as a guide so that the focus of research was in line with events in the field. The results showed the quality of service consisting of a) Reliability was that nurses were able to provide the promised service immediately and satisfactorily; $b$ ) Assurance was nurses had the knowledge, ability, hospitality, courtesy, and trustworthiness to eliminate consumer doubts; c) Tangible was the ability to provide tangible evidence of nursing services for patients; d) Empathy included the ability of nurses in terms of good communication, attention, understanding the personal needs of patients; e) Responsiveness was the desire or willingness of nurses to help and provide nursing services to patients. So the conclusion was that most of the informants felt happy and satisfied with nursing services but for the Responsiveness dimension many informants said they were not satisfied.
\end{abstract}

Peningkatan kualitas pelayanan, ketersediaan fasilitas, dan kemandirian menjadi tuntutan Rumah Sakit sebagai sub sistem kesehatan nasional. Dengan demikian rumah sakit dituntut untuk menyediakan pelayanan kesehatan yang bermutu serta dikelola oleh sumber daya keperawatan unggul sehingga dapat tercipta efisiensi, kualitas pelayanan, dalam memenuhi kebutuhan pasien. Tujuan penelitian ini Untuk menganalisis kualitas pelayanan keperawatan di RSUD Kota Baubau dengan menggunakan metode kualitatif, dimana penelitian ini lebih bersifat deskriptif serta analisa mendalam, menonjolkan perspektif subyektif dan landasan teori digunakan sebagai pemandu sehingga fokus penelitian searah dengan kejadian di lapangan. Hasil penelitian menunjukkan Kualitas pelayanan yang terdiri dari a) Reliability bahwa perawat mampu memberikan pelayanan yang dijanjikan dengan segera dan memuaskan; b) Assurance dimana perawat memiliki pengetahuan, kemampuan, ramah tamah, sopan, dan sifat dapat dipercaya untuk menghilangkan keragu-raguan konsumen; c) Tangible kemampuan memberikan bukti nyata dari pelayanan keperawatan untuk pasien; d) Empahty meliputi kemampuan perawat dalam hal komunikasi yang baik, perhatian, memahami kebutuhan pribadi pasien; e) Responsiveness merupakan Keinginan atau kemauan para perawat untuk membantu dan memberikan jasa keperawatan kepada pasien. Sehingga dapat ditarik kesimpulan bahwa sebagian besar informan merasakan senang dan puas terhadap pelayanan keperawatan namun untuk dimensi Responsivenes banyak informan mengatakan belum merasa puas.

\section{Corresponding Author:}

La Ode Syaiful Islamy H

Pascasarjana Administrasi Negara Universitas Dayanu Ikhsanuddin

Telp. 085397033570

Email: syaiful80islamy@gmail.com

\section{PENDAHULUAN}

Globalisasi telah memberi dampak positif bagi setiap profesi kesehatan untuk selalu berupaya meningkatkan kinerja profesionalnya dalam berkontribusi pada berbagai kebutuhan kesehatan masyarakat.
Hal ini sejalan dengan makin meningkatnya tuntutan masyarakat akan kualitas pelayanan kesehatan (Ratna Sitorus dan Yulia, 2006)

Menurut undang-undang Nomor 25

Tahun 2009 tentang pelayanan publik, 
mengamanatkan kepada seluruh institusi pemerintah, baik di tingkat pusat maupun di daerah, untuk melakukan analisis Kepuasan Masyarakat sebagai tolak ukur keberhasilan penyelenggaraan pelayanan. Kebijakan tersebut secara tegas mengatakan bahwa kualitas pelayanan publik ukurannya adalah kepuasan masyarakat.

pasien $\begin{array}{cccr}\text { Semakin } & \text { ketatnya } & \text { persaingan } & \text { serta } \\ \text { semakin } & \text { selektif } & \text { dan }\end{array}$ berpengetahuan mengharuskan RSUD Kota Baubau selaku salah satu penyedia jasa pelayanan kesehatan untuk selalu meningkatkan kualitas pelayanannya. Untuk dapat meningkatkan kualitas pelayanan, terlebih dahulu harus diketahui apakah pelayanan yang telah diberikan kepada pasien selama ini telah sesuai dengan harapan pasien atau belum. Hal ini penting dilakukan sebagai acuan dalam pembenahan pelayanan agar dapat memberikan kepuasan optimal, sehingga RSUD Kota Baubau dituntut untuk selalu menjaga kepercayaan dan kepuasan pasien dengan meningkatkan kualitas pelayanan agar kepuasan pasiennya meningkat. Pihak RSUD Kota Baubau dalam menentukan kebutuhan pasien sangat dibutuhkan kecermatan sebagai bagian dari upaya pemenuhan seluruh harapan serta kepuasan pasien serta atas pelayanan yang diberikan.

Masalah utama yang setiap saat dihadapi oleh lembaga jasa pelayanan kesehatan adalah semakin banyaknya kompetitor. Oleh karena itu, rumah sakit dihadapkan oleh tuntutan agar senantiasa menjaga kepercayaan pasien dengan menjaga kualitas pelayanan yang dimiliki sehingga kepuasan pasien terus terjaga. Pihak rumah sakit perlu secara cermat menentukan kebutuhan pasien sebagai upaya untuk memenuhi keinginan dan meningkatkan kepuasan atas pelayanan yang diberikan (John, 1992)

Melayani dan merawat pasien dengan berbagai karakter, perawat dituntut agar senantiasa mendengarkan suara dan keluhan pasien, serta merespon setiap keinginan, harapan bahkan tuntutan pasien. Hal ini berhubungan dengan kepuasan terhadap layanan keperawatan yang senantiasa mendampingi, merawat serta melayani pasien sebagai pengguna jasa kesehatan.

Di RSUD Kota Baubau untuk mengukur kepuasan pasien menggunakan metode Indeks Kepuasan Masyarakat (IKM) yang dilaksanakan oleh Bidang Pelayanan RSUD Kota Baubau setiap triwulan menunjukkan hasil yaitu: Triwulan Pertama 2017 didapatkan nilai indeks pelayanan setelah dikonversi $=78,5$ yang artinya kinerja unit pelayanan baik, Bulan April - Juni 2017 didapatkan nilai indeks pelayanan setelah dikonversi $=78,5$ yang artinya kinerja unit pelayanan baik, Bulan Juli - September 2017 didapatkan nilai indeks pelayanan setelah dikonversi $=77,8$ yang artinya kinerja unit pelayanan baik, Dan Bulan Oktober Desember 2017 didapatkan nilai indeks pelayanan setelah dikonversi $=74,5$ yang artinya kinerja unit pelayanan baik. Namun pengukuran IKM ini mengukur kinerja secara umum.

Hasil tersebut sejalan dengan penelitian yang dilakukan oleh Tasrifin Tahara tentang kualitas pelayanan publik dari beberapa bidang yang bersentuhan langsung dengan pelayanan pemerintahan di Kota Baubau termaksud dalam kategori baik. Namun, beberapa hal yang harus diperbaiki di antaranya kecepatan pelayanan, kewajaran biaya, keadilan pendapatan pelayanan, serta kedisiplinan petugas pelayanan. Dari kajian ini semua unit pelayanan publik diharapkan dapat memperbaiki kelemahan yang dimiliki dan mempertahankan serta meningkatkan kualitas pelayanan yang sudah baik (Tahara, 2018).

Berdasarkan pengamatan yang dilakukan, kepuasan pasien rawat inap pada RSUD Kota Baubau belum maksimal yang kemungkinan dipengaruhi oleh kualitas pelayanan keperawatan yang juga belum maksimal, Kepuasan Pasien rawat inap pada RSUD Kota Baubau yang belum maksimal dapat dilihat dari kurangnya tenaga keperawatan juga beragamnya kualifikasi tingkat pendidikan. Magister (S2) keperawatan 1 orang, Sarjana Keperawatan (S1 Ners) 26 orang, 68 orang berpendidikan D III keperawatan, dan lulusan SPK berjumlah 4 orang, dengan status kepegawaian 44 orang PNS dan tenaga sukarela berjumlah 51 orang. Selain itu masih banyaknya perawat yang tidak disiplin dalam bekerja serta masih ada perawat sukarela yang bekerja di dua tempat sekaligus sehingga tugas-tugasnya banyak yang terbengkalai, kemudian ada beberapa perawat yang tidak maksimal melaksanakan tugasnya dikarenakan berbagai halangan misalnya sakit 
dan Non Nursing Job sehingga dapat membebani perawat lain. Komunikasi sering menghambat kerja perawat disebabkan tata cara penyampaian dengan menggunakan kalimat yang kurang tepat sehingga terjadi kesalahpahaman antara perawat, pasien dan keluarga pasien.

\section{METODE PENELITIAN}

Penelitian ini menggunakan metode penelitian kualitatif. Pemilihan metode ini didasarkan pada teori atau model yang dijadikan rujukan dalam pengumpulan data tidak diuji proposisinya tetapi hanya diverifikasi atau dikonfirmasi dengan data-data lapangan.

\section{Jenis Penelitian}

Penelitian ini menggunakan Jenis penelitian studi kasus, jenis ini dipilih karena studi kasus secara umum cocok digunakan jika pokok pertanyaan dalam penelitian menggunakan pertanyaan how dan why.

\section{Lokasi dan Waktu Penelitian}

Penelitian ini berlokasi di RSUD Kota Baubau. Penelitian dilaksanakan pada bulan Agustus November 2018

\section{Informan \\ Informan Penelitian ini adalah Jajaran manajemen RSUD Kota Baubau yang berhubungan dengan perawatan pasien, serta pasien yang menjalani rawat inap berjumlah 10 orang.}

\section{Pengumpulan Data}

Pengumpulan data dilakukan dengan melakukan wawancara. Wawancara yang dilakukan in depth interview. Informan ini adalah yang berhubungan langsung dengan pelayanan keperawatan di RSUD Kota Baubau yang menjadi obyek penelitian ini yaitu: Kepala Bidang Keperawatan, Supervisor Keperawatan, perawat serta pasien sebagai penerima layanan keperawatan. Peneliti melakukan pengamatan lapangan.

Kegiatan ini sepenuhnya menjadi aktivitas peneliti secara aktif pada obyek penelitian untuk mengamati secara langsung berbagai aktivitas yang berkaitan dengan masalah yang diteliti. Terakhir peneliti melakukan pengumpulan data-data sekunder. penelusuran dokumentasi lembaga atau instansi. Lembaga atau instansi ditentukan berdasarkan fungsinya dan mempunyai keterkaitan dengan masalah yang diteliti.

\section{Pengolahan dan Analisis Data}

Dalam menganalisis data peneliti menggunakan Model analisis data Miles dan Huberman, berdasarkan model ini, analisis data dilaksanakan dalam 3 tahap, yaitu: reduksi data (data reduction), penyajian data (data display), dan penarikan kesimpulan dan verifikasi (conclusion drawing/verification) (Miles \& Huberman, 1992).

\section{HASIL}

Berdasarkan hasil wawancara dan pengamatan yang dilakukan selama 3 bulan ditemukan bahwa kualitas pelayanan keperawatan di RSUD Kota Baubau umumnya sudah baik. Dengan memperhatikan 5 dimensi kualitas pelayanan menurut Zeithaml, Berry dan Parasuraman ( yaitu, Reliability, Tangibles, Assurance, Responsiveness, dan Empathy (Rosalia, 2018).

Pada dimensi Reability Menurut hasil wawancara dengan informan bahwa pada dimensi Reliability ada 7 informan menjawab bahwa mereka sangat senang dan puas karena perawatnya sangat baik dan selalu memeriksa setiap harinya seperti mengukur tekanan darah, suhu, nadi dan pernapasan, walaupun dokter sering kali datangnya terlambat. Sedangkan 3 informan mengatakan pelayanan banyak mengalami perubahan dibanding beberapa tahun yang lalu dilihat dari perawatnya sudah sangat ramah dan sopan dan sangat memperhatikan pasien dan memeriksanya tepat waktu, akan tetapi perawatnya tidak memberitahukan tentang hal-hal yang dipatuhi dan dilarang di rumah RSUD Kota Baubau.

Dimensi Tangibles Berdasarkan hasil wawancara dan pengamatan bahwa pasien merasa nyaman dan aman sehingga tidak merasa ragu untuk melakukan perawatan kesehatan di rumah sakit walaupun diakui bahwa masih banyak fasilitas yang disediakan oleh pihak rumah sakit kurang memadai seperti alat Rotgent, CT Scan namun tidak menyurutkan keinginan dan kepercayaan masyarakat untuk berobat.

Selanjutnya pada dimensi Assurance dari hasil wawancara dengan informan ditemukan bahwa untuk segi assurance/jaminan 5 informan menjawab perawat yang ada di RSUD Kota Baubau sangat sopan, serta mereka 
selalu memperhatikan keluhan-keluhan dan menjelaskan semua pertanyaan yang ditanyakan oleh pasien, 3 informan mengatakan bahwa pengetahuan para perawat sangat meyakinkan ketika menjelaskan tentang hal hal apa yang menjadi keluhan tentang penyakitnya. Serta disiplin dan penuh kehati-hatian dalam melakukan perawatan pasien. 2 Informan menjawab Ruangan yang ada di RSUD Kota Baubau ini sangat rapi dan bersih petugas clinning servicenya tiap pagi dan sore.

Tabel 1. Reduksi Data Dimensi Reability

\begin{tabular}{|c|c|c|}
\hline Informan & $\begin{array}{c}\text { Kecenderungan Hasil } \\
\text { Wawancara }\end{array}$ & Makna/Arti \\
\hline Informan $2,3,5,6,7,9$, dan 10 & $\begin{array}{l}\text { Pasien sangat senang dirawat di } \\
\text { rumah sakit palagimata karena } \\
\text { perawatnya sangat baik dan selalu } \\
\text { memeriksa saya setiap harinya } \\
\text { seperti mengukur tekanan darah, } \\
\text { suhu, nadi dan pernapasan, walaupun } \\
\text { dokter sering kali datangnya } \\
\text { terlambat dan memberikan kami } \\
\text { resep sudah siang akan tetapi kami } \\
\text { puas karena sudah dilakukan oleh } \\
\text { perawat-perawat yang ada di Rumah } \\
\text { sakit palagimata ini. }\end{array}$ & $\begin{array}{l}\text { Perhatian yang diberikan perawat kepada } \\
\text { pasien akan menumbuhkan kepercayaan } \\
\text { bahwa mereka bisa sembuh bila berobat di } \\
\text { RSUD Kota Baubau walaupun pelayanan } \\
\text { medis sering terlambat tetapi sudah ada } \\
\text { perawat yang melakukan pelayanan } \\
\text { tersebut }\end{array}$ \\
\hline Informan $1,4,8$ & $\begin{array}{l}\text { Pelayanan di rumah sakit palagimata } \\
\text { ini sudah banyak mengalami } \\
\text { perubahan dibanding beberapa tahun } \\
\text { yang lalu, sekarang perawatnya } \\
\text { sudah sangat ramah dan sopan dan } \\
\text { sangat memperhatikan pasien dan } \\
\text { memeriksanya tepat waktu akan } \\
\text { tetapi perawatnya } \\
\text { memberitahukan tidak } \\
\text { tentang hal-hal yang dipatuhi dan di } \\
\text { larang di rumah sakit palagimata. }\end{array}$ & $\begin{array}{l}\text { Pemberian layanan pada RSUD kota } \\
\text { Baubau telah sesuai harapan pasien, } \\
\text { ketepatan waktu dalam melakukan tindakan } \\
\text { akan membuat pasien merasa puas, } \\
\text { walaupun perawat masih kurang } \\
\text { memberitahukan kepada pasien tentang } \\
\text { peraturan yang berlaku di RSUD Kota } \\
\text { Baubau }\end{array}$ \\
\hline
\end{tabular}

Tabel 2. Reduksi Data Dimensi Tangibles

\begin{tabular}{|c|c|c|}
\hline Informan & $\begin{array}{c}\text { Kecenderungan Hasil } \\
\text { Wawancara }\end{array}$ & Makna/Arti \\
\hline $\begin{array}{l}\text { Informan } 2,3,4,6,7 \text {, } \\
9, \text { dan } 10\end{array}$ & $\begin{array}{l}\text { Fasilitas fisik dan jenis jasa yang } \\
\text { diberikan di rumah sakit } \\
\text { palagimata memang sudah cukup } \\
\text { baik, namun tidak dapat } \\
\text { dipungkiri masih terdapat } \\
\text { kelemahan-kelemahan. }\end{array}$ & $\begin{array}{l}\text { Terjaminnya keamanan dan kenyamanan pada } \\
\text { rumah sakit senantiasa menciptakan suasana } \\
\text { aman pada pasien sehingga pasien akan } \\
\text { merasa terlindungi dan yakin untuk berobat. } \\
\text { Selain itu, akan meningkatkan kepercayaan } \\
\text { pasien. }\end{array}$ \\
\hline Informan 1 , dan, 8 & $\begin{array}{l}\text { Fasilitas yang ada di rumah sakit } \\
\text { palagimata belum memadai } \\
\text { seperti alat Rotgent, CT Scan, } \\
\text { namun saya tetap merasakan puas } \\
\text { pada pelayanan yang didapat } \\
\text { selama ini. }\end{array}$ & $\begin{array}{l}\text { RSUD Kota Baubau dalam memberikan } \\
\text { pelayanan telah memenuhi harapan pasien. } \\
\text { Ketepatan waktu dalam melakukan tindakan } \\
\text { akan membuat pasien merasa puas, walaupun } \\
\text { perawat masih kurang memberitahukan } \\
\text { kepada pasien tentang peraturan yang berlaku } \\
\text { di RSUD Kota Baubau }\end{array}$ \\
\hline Informan 5 & $\begin{array}{l}\text { Penampilan perawat rumah sakit } \\
\text { palagimata ini sangat rapi, dan } \\
\text { memakai seragam, pada hari } \\
\text { kamis namun Jumat mereka tidak } \\
\text { memakai pakaian seragam. }\end{array}$ & $\begin{array}{l}\text { Pasien menilai bahwa sebagian besar perawat } \\
\text { telah menggunakan seragam dengan rapi dan } \\
\text { pada hari Senin sampai hari Kamis, namun } \\
\text { pada hari Jumat pakaian bebas rapi begitu pula } \\
\text { dengan perawat yang sift malam. }\end{array}$ \\
\hline
\end{tabular}


Sedangkan pada dimensi Responsivennes setelah dilakukan wawancara ditemukan bahwa 6 informan mengatakan Lambatnya perawat dalam memberikan informasi tentang kehadiran dokter kecuali kita sendiri yang pergi tanya, apalagi kalau bertepatan dengan hari libur dokternya tidak datang memeriksa pasien, tetapi ada perawat yang selalu siap memperhatikan 24 jam, 3 informan mengatakan Perawat yang ada di rumah sakit palagimata ini sangat baik, memperhatikan pasien-pasien lainnya. Perawat di ruangan ini sangat cepat, cekatan dalam melakukan tindakan keperawatan pada saat melayani pasien, serta 1 informan mengatakan ingin kembali berobat di rumah sakit palagimata karena selama dirawat pelayanan yang diberikan sangat memuaskan.

Tabel 3. Reduksi Data Dimensi Assurance

\begin{tabular}{|c|c|c|}
\hline Informan & $\begin{array}{c}\text { Kecenderungan Hasil } \\
\text { Wawancara }\end{array}$ & Makna/Arti \\
\hline Informan $1,3,4,5,6,7,8$, dan 9 & $\begin{array}{l}\text { Perawat yang ada di rumah sakit } \\
\text { palagimata sangat sopan, serta } \\
\text { mereka selalu memperhatikan } \\
\text { keluhan-keluhan saya dan } \\
\text { menjelaskan semua pertanyaan dan } \\
\text { perawatan saya }\end{array}$ & $\begin{array}{l}\text { Perhatian yang diberikan } \\
\text { perawat kepada pasien akan } \\
\text { menumbuhkan kepercayaan } \\
\text { bahwa mereka bisa sembuh } \\
\text { bila berobat di RSUD Kota } \\
\text { Baubau. }\end{array}$ \\
\hline Informan 2, dan 10 & $\begin{array}{l}\text { Ruangan yang ada di rumah sakit } \\
\text { palagimata ini sangat rapi dan } \\
\text { bersih petugas clinning servicenya } \\
\text { tiap pagi dan sore selalu } \\
\text { membersihkan, membuat saya } \\
\text { sangat nyaman berada di ruangan } \\
\text { ini }\end{array}$ & $\begin{array}{l}\text { Pasien akan kembali berobat } \\
\text { di RSUD Kota Baubau karena } \\
\text { merasa nyaman akan } \\
\text { keberadaan disebabkan karena } \\
\text { lingkungannya yang bersih }\end{array}$ \\
\hline
\end{tabular}

Tabel 4. Reduksi Data Dimensi Responsivenes

\begin{tabular}{|c|c|c|}
\hline Informan & $\begin{array}{c}\text { Kecenderungan Hasil } \\
\text { Wawancara }\end{array}$ & Makna/Arti \\
\hline Informan $2,3,4,5,8,9$ & $\begin{array}{l}\text { Lambatnya perawat dalam } \\
\text { memberikan informasi tentang } \\
\text { kehadiran dokter, apalagi kalau } \\
\text { bertepatan dengan hari libur } \\
\text { biasanya dokternya tidak datang } \\
\text { memeriksa pasien, akan tetapi } \\
\text { untung ada perawat yang selalu siap } \\
\text { memperhatikan saya } 24 \text { jam. }\end{array}$ & $\begin{array}{l}\text { Daya tanggap perawat dalam } \\
\text { kecepatan perawat Untuk } \\
\text { memberikan informasi yang } \\
\text { dibutuhkan pasien, dan } \\
\text { kecepatan perawat dalam } \\
\text { menanggapi keluhan pasien } \\
\text { pada RSUD Kota Baubau } \\
\text { sudah signifikan dengan } \\
\text { harapan pasien sehingga rasa } \\
\text { kepuasan pengguna jasa } \\
\text { (pasien) belum terpuaskan }\end{array}$ \\
\hline $\begin{array}{l}\text { Informan } 1 \\
\text { Infoeman } 7\end{array}$ & $\begin{array}{l}\text { Perawat yang ada di rumah sakit } \\
\text { palagimata ini sangat baik, } \\
\text { memperhatikan saya dan pasien- } \\
\text { pasien lainnya. Perawat di ruangan } \\
\text { ini sangat cepat, cekatan dalam } \\
\text { melakukan tindakan keperawatan } \\
\text { pada saat melayani pasien. }\end{array}$ & $\begin{array}{l}\text { Pelayanan yang disajikan oleh } \\
\text { perawat telah memenuhi } \\
\text { harapan pasien yaitu } \\
\text { pelayanan yang ramah, sopan } \\
\text { dan handal dalam melakukan } \\
\text { tindakan. }\end{array}$ \\
\hline $\begin{array}{l}\text { Informan } 6 \\
\text { Informan } 10\end{array}$ & $\begin{array}{l}\text { Saya ingin kembali berobat di } \\
\text { rumah sakit palagimata karena } \\
\text { selama saya dirawat pelayanan } \\
\text { yang diberikan sangat memuaskan }\end{array}$ & $\begin{array}{l}\text { Pelayanan yang didapat } \\
\text { sangat baik dan memuaskan } \\
\text { sehingga pasien akan kembali } \\
\text { untuk berobat di RSUD Kota } \\
\text { Baubau jika merasakan sakit. }\end{array}$ \\
\hline
\end{tabular}


Dari hasil wawancara dengan informan ditemukan pada dimensi Emphaty/empati ada 6 informan mengatakan pelayanan yang diberikan perawat sangat baik dan tidak membedabedakan status sosial, agama, pangkat, jabatan serta asuransi yang dipakai oleh pasien dan lain-lain, serta dilayani dengan sepenuh hati, 2 informan mengatakan Perawat-perawat yang bertugas ramah-ramah dan sangat memperhatikan semua pasien, memberikan penjelasan apabila bertanya tentang penyakitnya serta 3 informan mengatakan perawat sangat memperhatikan keluhankeluhan yang dirasakan, perawatnya akan segera datang dan tidak perlu menunggu lama

Tabel 5. Reduksi Data Dimensi Empathy

\begin{tabular}{|c|c|c|}
\hline Informan & Kecenderungan Hasil Wawancara & Makna/Arti \\
\hline $\begin{array}{l}\text { Informan } 1,3, \\
4,5,6,8 \text {, dan } \\
9\end{array}$ & $\begin{array}{l}\text { Pelayanan yang diberikan perawat di rumah } \\
\text { sakit palagimata sangat baik dan tidak } \\
\text { membeda-bedakan status sosial, agama, } \\
\text { pangkat, jabatan serta asuransi yang dipakai } \\
\text { oleh pasien dan lain-lain, serta kami dilayani } \\
\text { dengan sepenuh hati. }\end{array}$ & $\begin{array}{l}\text { Pelayanan yang diberikan di RSUD Kota } \\
\text { Baubau dan melihat pelayanan yang } \\
\text { didapatkan telah sesuai dengan apa yang } \\
\text { diharapkan sehingga pasien senantiasa } \\
\text { merasa puas dengan pelayanan yang } \\
\text { diberikan. }\end{array}$ \\
\hline $\begin{array}{l}\text { Informan } \\
\text { dan } 7\end{array}$ & $\begin{array}{l}\text { Perawat-perawat yang bertugas di rumah sakit } \\
\text { palagimata ini ramah-ramah dan sangat } \\
\text { memperhatikan semua pasien, memberikan } \\
\text { penjelasan apabila pasien bertanya tentang } \\
\text { penyakitnya. }\end{array}$ & $\begin{array}{l}\text { Rasa empati yang diberikan oleh perawat } \\
\text { kepada pasien yang terdiri dari Perhatian } \\
\text { perawat, hubungan perawat dengan } \\
\text { pasien dan hubungan perawat dan } \\
\text { keluarga pasien pada RSUD kota Baubau } \\
\text { sudah memuaskan pengguna jasa. }\end{array}$ \\
\hline Informan 10 & $\begin{array}{l}\text { Petugas di rumah sakit palagimata sangat } \\
\text { memperhatikan keluhan-keluhan yang saya } \\
\text { rasakan, apabila dipanggil perawatnya akan } \\
\text { segera datang dan kami tidak perlu menunggu } \\
\text { lama }\end{array}$ & $\begin{array}{l}\text { Ketepatan waktu yang diberikan perawat } \\
\text { RSUD Kota Baubau menjadikan pasien } \\
\text { puas akan pelayanan yang diberikan. }\end{array}$ \\
\hline
\end{tabular}

\section{PEMBAHASAN}

Kualitas Pelayanan keperawatan adalah suatu proses kegiatan yang dilaksanakan oleh perawat dalam memenuhi kebutuhan pasien dalam mempertahankan keadaan dari segi biologis, psikologis, sosial, dan spiritual pasien (Suarli dan Bahtiar, 2012).

\section{Reliability}

Reliability (kehandalan); merupakan kemampuan memberikan pelayanan yang dijanjikan dengan cepat, tepat dan memuaskan. Keandalan dapat dimaknai mampu mengerjakan dengan baik dalam kurun waktu tertentu. Pemenuhan jaminan kualitas pelayanan yang tepat dan memuaskan mencakup ketepatan waktu dan kecakapan dalam merespon kebutuhan pasien serta pemberian pelayanan dengan akurat dan wajar.

$\mathrm{Hal}$ tersebut menunjukkan bahwa Reliability/kehandalan dari para petugas kesehatan dalam hal ini perawat dapat memberikan kepuasan pada pasien. Kemampuan perawat dalam memberikan layanan yang dibutuhkan dengan tepat cepat, dan akurat, serta memuaskan. perlakuan yang adil antara pasien umum dan peserta jaminan kesehatan nasional, kecakapan perawat saat berkomunikasi dan memberikan informasi kesehatan, pemenuhan kebutuhan pasien, serta kesigapan perawat dalam merawat pasien.

Hasil penelitian ini sesuai dengan penelitian yang dilaksanakan oleh Meutia Dewi dengan kajian pelayanan Pengaruh Kualitas Pelayanan terhadap Kepuasan Pasien Pengguna BPJS pada Rumah Sakit Rehabilitasi Medik Kabupaten Aceh Timur menyimpulkan bahwa pelayanan yang diberikan pihak rumah sakit saat pada pasien telah dilaksanakan dengan baik, namun tidak dapat dipungkiri masih ditemukan beberapa kelemahan-kelemahan dalam melakukan pelayanan misalnya pada kehandalan, masih ada perawat dalam melakukan pelayanan masih terkesan lambat, untuk itu para tenaga medis diharapkan mampu memberikan pelayanan yang tepat dan cepat kepada pasien (Dewi, 2016). 


\section{Tangibles}

Tangibles/bukti fisik; terdiri dari fasilitas, sarana dan prasarana serta perlengkapan yang dimiliki pegawai, komunikasi serta kendaraan operasional. sehingga bukti langsung/wujud merupakan satu indikator yang paling konkret. Wujudnya berupa segala fasilitas yang nampak secara nyata. Tangible/bukti fisik menjadi dimensi yang mempengaruhi kepuasan pasien unit rawat inap RSUD kota Baubau. ini menunjukkan bahwa semakin besarnya bukti fisik atau Tangible seperti perawatan pasien, jaminan keamanan saat berada di ruang rawat inap, kecakapan perawat dalam merawat pasien menunjukkan semakin tinggi tingkat kepercayaan pasien terhadap RSUD Kota Baubau.

Hasil penelitian sejalan dengan penelitian yang dilaksanakan oleh Meutia Dewi yang menyimpulkan bahwa Kualitas pelayanan yang diberikan pihak Rumah Sakit Rehabilitasi Medik Kabupaten Aceh Timur pada setiap pasiennya telah terlaksana dengan baik, akan tetapi masih terdapat kelemahan dalam pelayanan yaitu bukti fisik masih adanya pembedaan fasilitas bagi peserta BPJS, sehingga diharapkan fasilitas yang diberikan pada setiap pasien diberlakukan sama (Dewi, 2016).

\section{Assurance}

Assurence/jaminan; mencakup hal yang berkaitan dengan pengetahuan dan pemahaman terhadap tugas, kemampuan, sopan santun dan sifat amanah yang dimiliki perawat, secara aman bebas dari risiko dan keraguan. pasien dan keluarga pasien selalu membersihkan, membuat sangat nyaman berada di rungan ini.

$\mathrm{Hal}$ ini dapat dinilai dari perhatian yang diberikan oleh perawat serta sikap profesional yang ditunjukkan dengan pemahaman tentang apa yang mesti dilakukan untuk kenyamanan pasien sehingga pasien terhindar dari keraguraguan untuk berobat di rumah sakit.

Hasil penelitian sejalan dengan penelitian yang dilakukan oleh Oktarina Dina tentang Analisis Pengaruh Kualitas terhadap kepuasan konsumen di Rs St. Elisabeth dimensi Semarang menyimpulkan bahwa dimensi Assurance atau Jaminan sangat mendominasi kepuasan pasien di RS Elisabeth Semarang adalah (Khasanah \& Pertiwi, 2010).

\section{Responsiveness}

Responsiveness atau daya tanggap; yaitu sikap tanggap juga cekatan perawat saat memberikan perawatan kepada pasien serta menyajikan pelayanan yang dibutuhkan dengan tepat, cepat dan cermat. Ketepatan serta kecepatan yang disajikan perawat kepada pasien merupakan buah dari pemahaman dan kecerdasan yang diperlihatkan kepada pasien.

Umumnya informan menyakatakan kepuasannya terhadap responsiveness yang diberikan oleh para perawat, namun ada beberapa kelemahan yang sering perlihatkan para perawat yaitu mereka kurang tanggap terhadap informasi kehadiran dokter di rumah sakit untuk melakukan pemeriksaan. Waktu kehadiran dokter yang tidak menentu membuat pasien merasa was-was dan tidak nyaman. Perawat tidak pernah memberi tahu pasien tentang ketepatan jadwal dokter sehingga pasien harus mempertanyakan sendiri kapan dokter akan melakukan pemeriksaan.

Hasil temuan sejalan dengan penelitian yang dilakukan oleh Rahadi Fitra Nova (2010) yang meneliti tentang pengaruh kualitas pelayanan terhadap kepuasan pasien rawat inap pada rumah sakit PKU Muhammadiyah Surakarta menyimpulkan bahwa Variabel ketanggapan ada pengaruh yang signifikan terhadap kepuasan pasien rawat inap, artinya apabila ketanggapan pelayanan ditingkatkan, maka kepuasan pasien rawat inap akan mengalami peningkatan

\section{Empathy}

Emphaty/empati; meliputi memberikan kemudahan hubungan dengan pelanggan, berkomunikasi dengan baik serta paham akan kebutuhan pelanggan. Empati yaitu perhatian yang diberikan individu kepada pasien dengan memosisikan dirinya secara pribadi pada situasi yang sama dengan pasien.

Hal ini menunjukkan bahwa dimensi Emphaty sangat mempengaruhi kepuasan pasien pada unit rawat inap di RSUD Kota Baubau. Emphaty yang ditunjukkan para perawat meliputi Rasa penghargaan dan perhatian, rasa mengerti dan berusaha memahami apa yang dikeluhkan pasien, sehingga banyak pasien merasa diperlakukan dan diperhatikan secara khusus oleh perawat.

Hasil penelitian ini searah dengan penelitian yang dilaksanakan oleh Kiky Jenitha Rosalia dan Niketut Purwanti (2015) tentang 
Pengaruh kualitas pelayanan terhadap kepuasan pasien RSU Surya Husadha di Denpasar menyimpulkan bahwa Pengaruh variabel empati memiliki pengaruh yang positif dan signifikan terhadap kepuasan pasien RSU Surya Husada Denpasar (Rosalia, 2018).

\section{KESIMPULAN DAN SARAN}

Kualitas Pelayanan keperawatan merupakan proses kegiatan yang dilaksanakan oleh profesi keperawatan dalam pemenuhan kebutuhan pasien dalam mempertahankan keadaan dari segi biologis, psikologis, spiritual, dan sosial pasien. Kualitas pelayanan keperawatan adalah asuhan keperawatan profesional yang mengacu pada 5 dimensi kualitas pelayanan yaitu, (Reliability, Tangibles, Assurance, Responsiveness, dan Empathy). Berdasarkan hasil wawancara ditemukan kualitas pelayanan keperawatan di RSUD Kota Baubau pada umumnya pasien merasakan kepuasan. Namun ada hal-hal yang menjadi kelemahan untuk dapat dimaksimalkan ke depannya seperti kurang disiplinnya tenaga keperawatan untuk merawat pasien hal ini terlihat pada adanya keluhan tentang kurang tanggapnya perawat untuk memberikan informasi mengenai kedatangan dokter.

Selain itu manajemen RSUD Kota Baubau telah menerapkan Model Praktik Keperawatan Profesional (MPKP) untuk menutupi segala kelemahan-kelemahan yang ada di rumah sakit. Sebaiknya manajemen RSUD Kota Baubau dapat meningkatkan kualitas pelayanan medis maupun non medis. Peningkatan kualitas pelayanan medis dapat dilaksanakan dengan cara mengarahkan manajemen rumah sakit pada peningkatan kualitas pelayanan yang berorientasi pada kepuasan pasien. RSUD kota Baubau sebaiknya lebih fokus pada lima dimensi kualitas pelayanan, khususnya pada dimensi responsiveness/daya tanggap disebabkan masih kurang disiplinnya para perawat dalam melaksanakan fungsi keperawatannya, serta kurang cepat dalam melayani pasien. Demikian juga dimensi yang lainnya tetap dipertahankan sehingga kepuasan pasien tetap terjaga.

\section{DAFTAR PUSTAKA}

Andung, P. J. R. (2017). Gambaran Kinerja Perawat Dalam Penerapan Metode
Asuhan Keperawatan Profesional (Makp) Modifikasi Tim-Primer di Ruangan Dahlia RSUD Umbu Rara Meha Waingapu Sumba Timur Pendrita. Nursing News, 2(3), 746-758.

Assauri, S. (2003). Customer Service yang Baik Landasan Pencapaian Customer Satisfaction dalam Usahawan. Tahun XXXII, 01 .

Dewi, M. (2016). Pengaruh Kualitas Pelayanan terhadap Kepuasan Pasien Pengguna BPJS pada Rumah Sakit Rehabilitasi Medik Kabupaten Aceh Timur. Manajemen dan Keuangan, 5(2), 535.

John, J. (1992). Patient satisfaction: the impact of past experience. Journal of Health Care Marketing, 12(3).

Khasanah, i., \& Pertiwi, O. D. (2010). Analisis Pengaruh Kualitas Pelayanan terhadap Kepuasan Konsumen RS St. Elisabeth Semarang. Jurnal Ekonomi Universitas Diponegoro, 12(2), 1-8.

Miles, M. B., \& Huberman, M. (1992). Analisis Data Kualitatif: Buku tentang sumbersumber baru. Universitas Indonesia. Jakarta.

Nova, R. F. (2010). Pengaruh Kualitas Pelayanan Terhadap Kepuasan Pasien Rawat Inap pada Rumah Sakit PKU Muhammadiyah Surakarta. Universitas Sebelas Maret.

Rahmi Surayya. (2018). Pendekatan kualitatif dalam penelitian kesehatan. Jurnal Kedokteran Dan Kesehatan Malikussaleh, 75-84.

Ratna Sitorus dan Yulia. (2006). Model praktik keperawatan profesional di rumah sakit. Jakarta: EGC.

Rosalia, K. J. (2018). Pengaruh Kualitas Pelayanan Terhadap Kepuasan Pasien RSU Surya Husadha Di Denpasar. EJurnal Manajemen Unud, Vol. 7, No, 2442-2469.

https://doi.org/https://doi.org/10.24843/E JMUNUD.2018.v7.i05.p05

Suarli dan Bahtiar. (2012). Manajemen Keperawatan dengan Pendekatan Praktis. Jakarta: Erlangga.

Tahara, T. (2018). Kajian Kualitas Pelayanan Publik Kota Baubau. Baubau. 